\title{
Core Flow Distribution from Coupled Supercritical Water Reactor Analysis
}

\author{
Po Hu${ }^{1}$ and Paul P. H. Wilson ${ }^{2}$ \\ ${ }^{1}$ School of Nuclear Science and Engineering, Shanghai Jiao Tong University, Shanghai 200240, China \\ ${ }^{2}$ Department of Engineering Physics, University of Wisconsin-Madison, Madison, WI 53705, USA
}

Correspondence should be addressed to Po Hu; pohu@sjtu.edu.cn

Received 6 January 2014; Revised 9 April 2014; Accepted 10 April 2014; Published 15 May 2014

Academic Editor: Jiejin Cai

Copyright (C) 2014 P. Hu and P. P.H Wilson. This is an open access article distributed under the Creative Commons Attribution License, which permits unrestricted use, distribution, and reproduction in any medium, provided the original work is properly cited.

\begin{abstract}
This paper introduces an extended code package PARCS/RELAP5 to analyze steady state of SCWR US reference design. An $8 \times$ 8 quarter core model in PARCS and a reactor core model in RELAP5 are used to study the core flow distribution under various steady state conditions. The possibility of moderator flow reversal is found in some hot moderator channels. Different moderator flow orifice strategies, both uniform across the core and nonuniform based on the power distribution, are explored with the goal of preventing the reversal.
\end{abstract}

\section{Introduction}

The supercritical water reactor (SCWR) is a next generation nuclear reactor concept. It is essentially a light water reactor (LWR) operating at higher pressure and temperature with a direct cycle. Its higher thermal efficiency and considerable plant simplification have distinguished it from the current reactors. Oka and his team presented both a thermal and fast SCWR design $[1,2]$, and Buongiorno presented a thermal SCWR as the US reference design [3], and Kim et al. and Xu et al. presented various mixed spectrum (thermal/fast) SCWR designs $[4,5]$.

In the US reference SCWR design, the majority of the coolant firstly flows downward as a dedicated moderator in separated water rods and then flows upward adjacent to the fuel pins as coolant. Because of the large change in water density through the pseudocritical point, heat transfer between the coolant and the moderator has an important impact in accurate SCWR reactor analysis. This paper uses an extended code package, which couples the core simulator PARCS to the thermal-hydraulics simulator RELAP5, to analyze both steady state and transient of SCWR design. An $8 \times 8$ quarter core model in PARCS and a reactor core model in RELAP5 [6] are used to study the core flow distribution under various steady state conditions.

\section{Analysis Methodology}

2.1. Extended Code Package. PARCS is a 3D core simulator using the nodal method to solve diffusion equation. It is able to analyze PWR and BWR designs in which water is used as both coolant and moderator in a single flow channel. In this work, PARCS was modified to accommodate thermal-hydraulic feedback to the nuclear cross-sections of the separated coolant and moderator channels in SCWR. In addition, changes have been made to the communication between PARCS and RELAP5 to accommodate these separate flows [7].

To enable the feedback from separated moderator, a new subroutine is added to look up macroscopic/homogenized cross-section information based on three thermal hydraulic properties: fuel temperature, coolant density, and moderator density. The homogenized cross-section data is prepared by the lattice transport code HELIOS [8].

Coupled PARCS and RELAP5 use lookup files to share information between corresponding computational units (nodes for PARCS, hydrodynamic volumes, and heat structures for RELAP5). In the original lookup file, the nodes in PARCS correspond to the hydrodynamic volumes representing the single fluid and the heat structures representing 

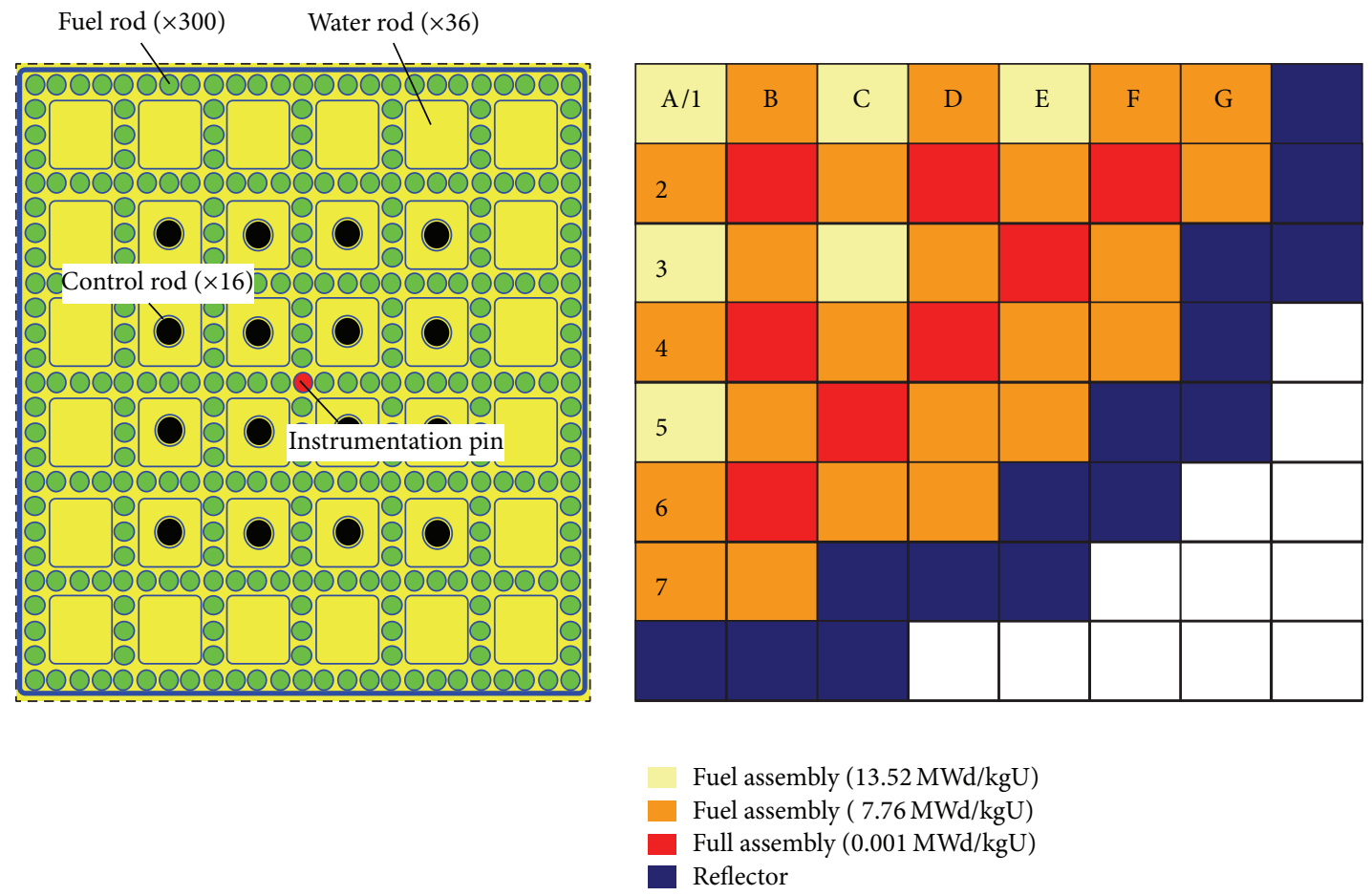

FIGURE 1: Fuel assembly and quarter core assembly arrangement.

fuel, cladding, and other core structure components in two separate tables. After the modification, there are three tables in the lookup file: one representing the coolant hydrodynamic volumes, one representing the moderator channel hydrodynamic volumes, and one representing the heat structures.

2.2. Core Models. An $8 \times 8$ quarter core model is used in PARCS, as show in Figure 1, with water reflectors at lateral boundaries and reflective boundary condition at top and bottom of the core. The fuel arrangement shown in Figure 1 is used in all the following calculations. These particular burnups were chosen to give an indication of the effect of burnup; a real equilibrium core loading would have larger burnups for partially used fuel. After considerations for symmetry, the 37 fuel assemblies in the PARCS model are coupled to 21 unique flow paths in the RELAP5 model. Both the PARCS and RELAP5 models have 12 axial nodes through the core. Flow paths in downcomer, moderator upper plenum, core, and lower plenum are modeled in RELAP5. A schematic of the flow path is shown in Figure 2; a moderator channel and a coolant channel represent one assembly in the core. In addition to being in contact with the fuel heat structure, the coolant channel is thermally coupled to the moderator channel through another heat structure representing the moderator channel wall. The majority of the inlet flow (90\%) to the core flows up to the moderator upper plenum and

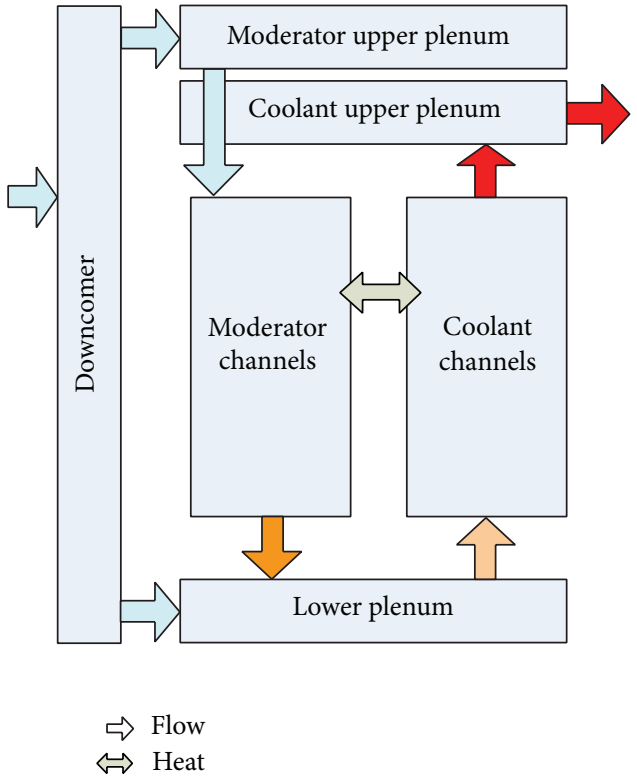

FIgURE 2: Flow pattern in RELAP5.

then flows downward through moderator channels. Next, all the moderator flow mixes with the downcomer flow and finally flows upwards through coolant channels and the coolant upper plenum and to the outlet of vessel. The design parameters are shown in Table 1. Previous research 
TABLE 1: SCWR nominal design parameters (Buongiorno et al., 2003 [3]).

\begin{tabular}{|c|c|c|c|}
\hline \multicolumn{2}{|c|}{ Fuel pin } & \multicolumn{2}{|c|}{ Core } \\
\hline Fuel material & $\mathrm{UO}_{2}$ & Thermal power & $3575 \mathrm{MW}$ \\
\hline Fissile enrichment & $5 \%$ & Number of fuel assemblies & 148 \\
\hline Fuel radius & $0.436 \mathrm{~cm}$ & Active height & $4.27 \mathrm{~m}$ \\
\hline Cladding material & Stainless steel & Effective diameter & $3.93 \mathrm{~m}$ \\
\hline Cladding thickness & $0.063 \mathrm{~cm}$ & Volumetric power density & $69 \mathrm{MW} / \mathrm{m}^{3}$ \\
\hline Fuel pitch & $1.12 \mathrm{~cm}$ & Average linear heat rate & $19.2 \mathrm{~kW} / \mathrm{m}$ \\
\hline $\mathrm{P} / \mathrm{D}$ & 1.12 & & \\
\hline \multicolumn{2}{|c|}{ Fuel assembly } & \multicolumn{2}{|c|}{ Thermal-hydraulic parameters } \\
\hline Number of fuel rods & 300 & System pressure & $25 \mathrm{MPa}$ \\
\hline Number of water rods & 36 & Coolant flow rate & $1843 \mathrm{~kg} / \mathrm{s}$ \\
\hline Number of control rods & 16 & Moderator bypass, $\beta$ & $10 \%(184 \mathrm{~kg} / \mathrm{s})$ \\
\hline Assembly pitch & $28.6 \mathrm{~cm}$ & Inlet temperature & $280^{\circ} \mathrm{C}$ \\
\hline Water rod width & $3.36 \mathrm{~cm}$ & Outlet temperature & $500^{\circ} \mathrm{C}$ \\
\hline Water rod wall thickness & $0.04 \mathrm{~cm}$ & Thermal efficiency & $44.80 \%$ \\
\hline
\end{tabular}

TABLE 2: Moderator flow rate and assembly power in the reference case.

\begin{tabular}{|c|c|c|c|c|c|c|c|}
\hline Flow rate $(\mathrm{kg} / \mathrm{s})$ & -15.6 & -13.6 & -15.2 & -13.7 & -15.7 & -15.5 & -17.1 \\
\hline Power (MW) & 25.2 & 27.7 & 25.7 & 27.3 & 24.8 & 25.3 & 18.2 \\
\hline Flow rate $(\mathrm{kg} / \mathrm{s})$ & -13.6 & -7.5 & -13.1 & 3.6 & -13.6 & -13.7 & -17.2 \\
\hline Power (MW) & 27.7 & 26.8 & 27.8 & 24.8 & 27.4 & 27.4 & 16.1 \\
\hline Flow rate $(\mathrm{kg} / \mathrm{s})$ & -15.2 & -13.1 & -14.8 & -12.9 & -11.4 & -16.5 & \\
\hline Power (MW) & 25.7 & 27.8 & 26.3 & 27.9 & 28.3 & 22.5 & \\
\hline Flow rate $(\mathrm{kg} / \mathrm{s})$ & -13.7 & 3.6 & -12.9 & -10.4 & -15.6 & -17.2 & \\
\hline Power (MW) & 27.3 & 24.8 & 27.91 & 28.2 & 25.0 & 16.6 & \\
\hline Flow rate $(\mathrm{kg} / \mathrm{s})$ & -15.7 & -13.6 & -11.4 & -15.6 & -17.1 & & \\
\hline Power (MW) & 24.8 & 27.4 & 28.3 & 25.0 & 17.9 & & \\
\hline Flow rate $(\mathrm{kg} / \mathrm{s})$ & -15.5 & -13.7 & -16.5 & -17.2 & & & \\
\hline Power (MW) & 25.3 & 27.4 & 22.5 & 16.6 & & & \\
\hline Flow rate $(\mathrm{kg} / \mathrm{s})$ & -17.1 & -17.2 & & & & & \\
\hline Power (MW) & 18.2 & 16.1 & & & & & \\
\hline
\end{tabular}

[9] showed that the heat transfer between the coolant and moderator channels could reduce the axial power peak by changing the equivalent moderator density, which represents combined moderation from moderator and coolant. These results were generated with a thermal hydraulic model inside PARCS assuming a fixed flow distribution in both moderator and coolant channels. This paper studies flow distributions in steady state using coupled PARCS/RELAP5. The possibility of moderator flow reversal is found in some hot moderator channels. Different moderator flow orifice strategies, both uniform across the core and nonuniform based on the power distribution, are explored with the goal of preventing the reversal.

\section{Reference Case}

The reference model uses a uniform orifice size for each moderator flow channel, with a ratio of the orifice area to the moderator area of 0.20 . This results in flow reversal in some moderator channels as shown in Table 2. Negative flow rates indicate a downward flow, as intended. These results show that two assemblies have reverse flow.

3.1. Pressure Balance in Moderator Channel. Due to buoyancy, the flow rate in hot moderator channels is lower than the flow rate in colder moderator channels. In most of moderator channels, a stable downward flow occurs as designated. In the highest power channels, due to the large density change through the pseudocritical point, the buoyancy effect is so large that the stable flow can be changed to flow upwards. This can result in a stable core flow distribution in which the flow in few moderator channels is upward while the flow in the rest of moderator channels is downward.

A reactor core designed with downward moderator flow may not behave well when the flow reverses; as unexpected, reversed channels will have power peak at the bottom for both moderator and coolant that are flowing upwards and their densities are decreasing accordingly, and these peaks may be difficult to deal with during the depletion considering the control rods withdrawing from the top of the core, and 

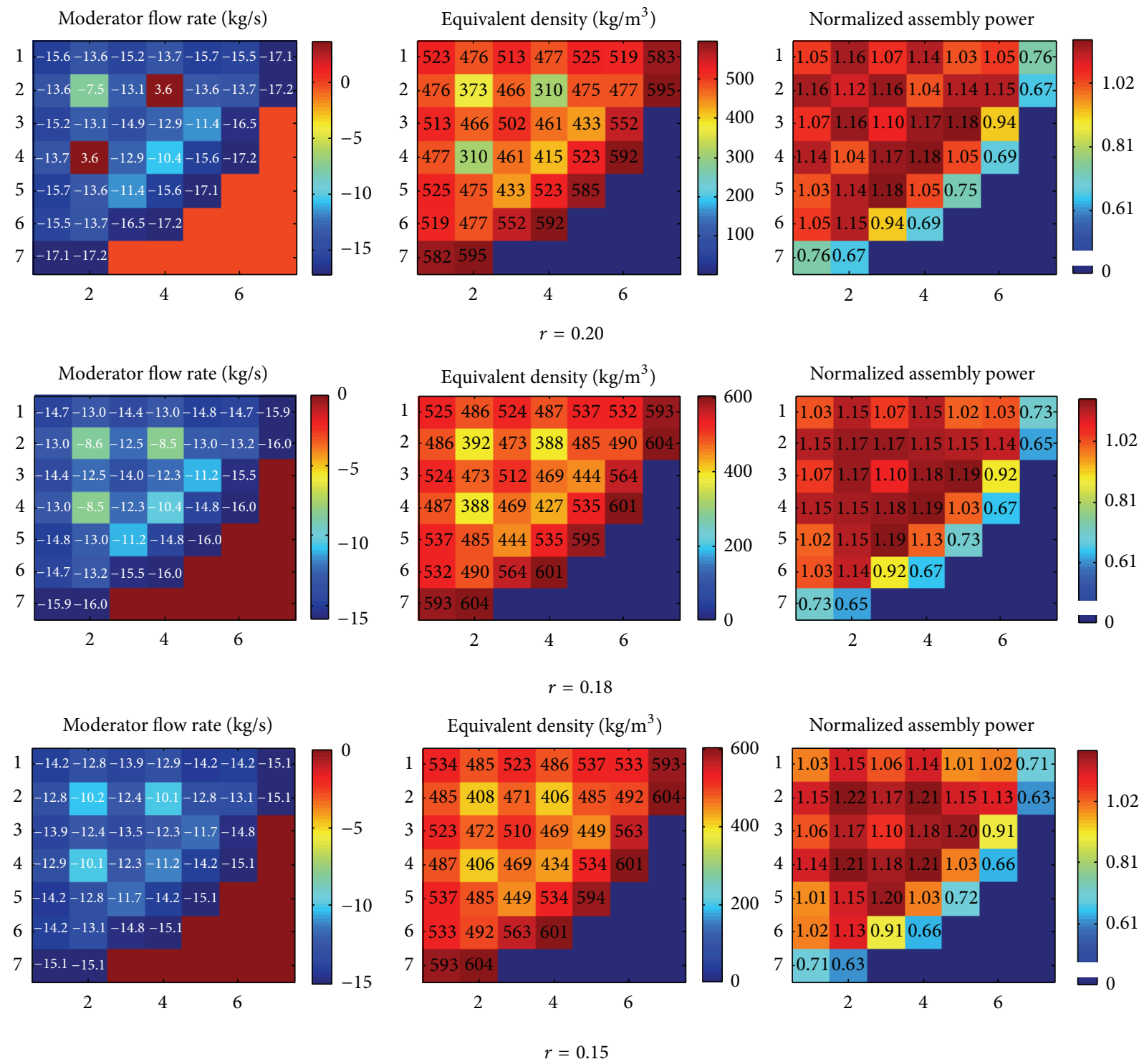

Normalized assembly power

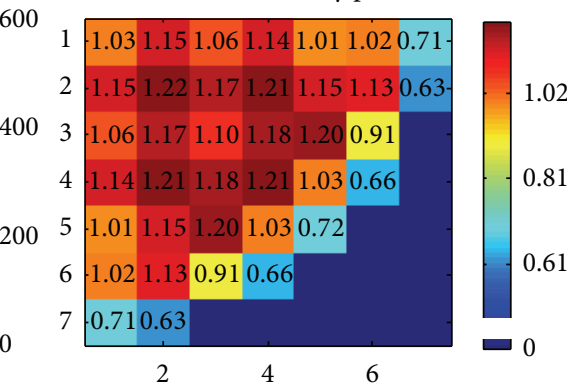

FIGURE 3: Moderator flow rate, equivalent density, and normalized assembly power (reference value $24.59 \mathrm{MW}$ ) in different orifice area ratio $r=A_{o} / A_{\text {mod }}$.

the flow reversal may vanish over the cycle. Therefore, it is important to study the circumstances under which this reversal occurs. Furthermore, there are at least two ways to manage/prevent the moderator flow reversal. A thermalhydraulics approach based on flow orifices in the moderator channels is discussed here. A neutronics approach based on using control rods, burnable absorbers, and axial fuel enrichment variance to change the power distribution will be studied in the future [10].

As shown in Figure 2, moderator enters the channel from the moderator upper plenum, flows downwards in the channel, and then exits to the lower plenum. The pressure balance through the moderator channel is dominated by three terms: the elevation pressure loss (gain in this case) and the entrance/exit pressure losses. The pressure balance can be written as follows:

$$
\int_{\text {in }}^{\text {out }} \rho g d l-\frac{1}{2 A_{\text {mod }}^{2}} \frac{K \dot{m}^{2}}{\rho_{o}}=\Delta P
$$

where $\Delta P$ represents the pressure difference of upper and lower plenum for an individual channel. In RELAP5, the abrupt orifice friction lost coefficient is defined as [11]

$$
K=\left(\frac{A_{\bmod }}{A_{c}}-1\right)^{2},
$$



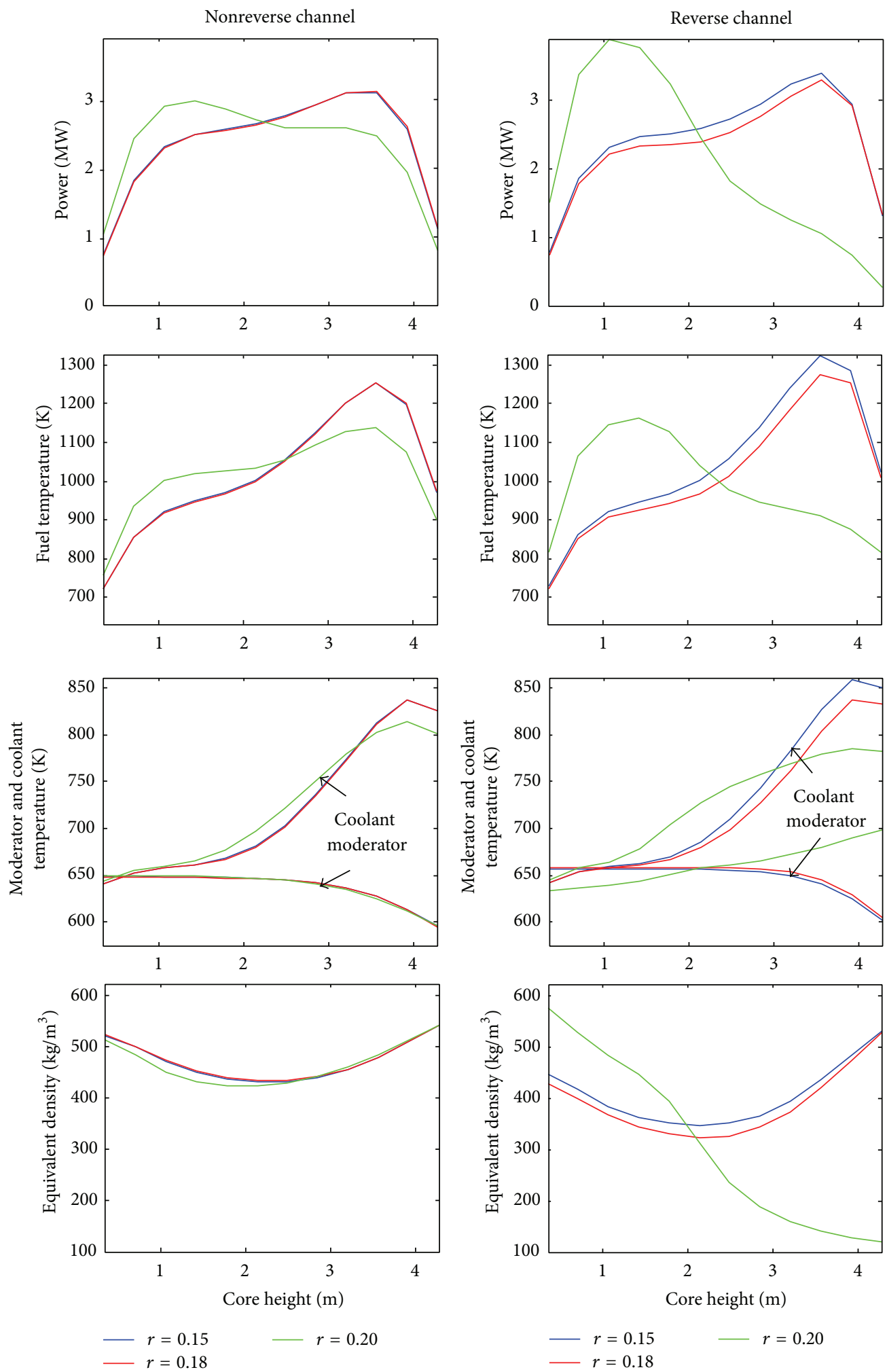

FIGURE 4: Power, fuel temperature, moderator and coolant temperature, and equivalent density profiles in three assemblies for three orifice cases. 
where $A_{c}$ is the physical minimum flow area. It is defined as

$$
A_{c}=0.62 A_{o}+0.38 \frac{A_{o}^{4}}{A_{\text {mod }}^{3}},
$$

where $A_{o}$ is cross-section of orifice and $A_{\text {mod }}$ is cross-section of moderator channel.

Since the hot channel has a lower water density than the normal channel, the elevation pressure loss is lower. To balance (1), the flow rate in the hot channel has to decrease. However, by reducing the orifice size $A_{o}$, the increased loss coefficient $K((2)$ and (3)) suggests that a smaller change in mass flow rate is needed and the reversal can be prevented. While the neutronics may mitigate the effect because of the lower moderation due to lower density in the hot channel, a coupled analysis will be helpful to investigate the possibility of this reversal.

In the following section, the results from three uniform orifice size cases are displayed followed by the results from one case with varied orifices corresponding to different assembly powers.

\section{Results}

4.1. Uniform Orifice Case. The results in Figures 3 and 4 are generated at the beginning of cycle for three different uniform orifice sizes, indicated by the ratio of their area to the moderator channel area, $r$. The fuel arrangement is shown in Figure 1. There are no control rods or burnable absorbers used in this problem.

Figure 3 shows moderator flow rate, equivalent density, and total assembly power in each assembly of the quarter core. The equivalent density is defined as

$$
\rho_{\mathrm{eq}}=\frac{\sum_{i=1}^{12}\left(\rho_{\mathrm{cool}, i} V_{\mathrm{cool}, i}+\rho_{\mathrm{mod}, i} V_{\mathrm{mod}, i}\right)}{\sum_{i=1}^{12}\left(V_{\mathrm{cool}, i}+V_{\mathrm{mod}, i}\right)},
$$

where the summation is over the 12 axial nodes, $i$. The results for $r=0.20$ are repeated here for comparison purposes and show the reversed flow in the moderator channels of two assemblies. As the area ratio is reduced to $r=0.18$, the flow reversal is avoided and downward flow occurs in all assemblies. The assembly power for those assemblies increases because the average equivalent density increases, improving the overall moderation. With further reduction in the orifice area, to $r=0.15$, even more of the moderator flow is distributed to the assemblies that previously showed reverse moderator flow. Although the equivalent density is still much lower than the other assemblies, these assemblies are now the highest power assemblies in the core.

Figure 4 shows the axial variations in the assembly power, coolant and moderator temperatures, and equivalent density for an assembly that experiences flow reversal (2D) and for an assembly that does not (2C). In the reference case, the power distribution is shifted towards the bottom of the core since the flow reversal reduces the moderation in the top of the core. Although the nonreversed assemblies do not experience any local reduction in the moderation (equivalent density), their power distribution is shifted down somewhat.
TABLE 3: Orifice arrangement.

\begin{tabular}{ccccccc}
\hline 0.2 & 0.2 & 0.2 & 0.2 & 0.2 & 0.2 & 0.2 \\
0.2 & 0.25 & 0.2 & 0.25 & 0.2 & $\mathbf{0 . 2 2 5}$ & 0.2 \\
0.2 & 0.2 & 0.2 & 0.2 & $\mathbf{0 . 2 2 5}$ & 0.2 & \\
0.2 & 0.25 & 0.2 & $\mathbf{0 . 2 2 5}$ & 0.2 & 0.2 & \\
0.2 & 0.2 & $\mathbf{0 . 2 2 5}$ & 0.2 & 0.2 & & \\
0.2 & $\mathbf{0 . 2 2 5}$ & 0.2 & 0.2 & & & \\
0.2 & 0.2 & & & & & \\
\hline
\end{tabular}

The largest local power density in the core is found in the reversed channel even though it is not the highest power assembly in the reference case. By contrast, in the cases with flow reversal suppressed, $r=0.18$ and $r=0.15$, the axial power distribution is similar in all assemblies, including the highest power assemblies in which flow reversal occurred with $r=0.20$. One apparent benefit to the downward shifted power distribution is a reduction in cladding/fuel temperatures since the maximum power occurs at a location with lower coolant temperatures. However, the strong axial variation in power for the reversed channel could present other problems. In particular, as a result of nonuniform burnup, the flow reversal may vanish over the cycle as the axial power distribution in these channels responds.

Based on the results of Figures 3 and 4, it is possible to prevent the reversal by using uniform orifice area ratio, $r<$ 0.18 , though from consideration of safety margin a lower value is preferred.

4.2. Nonuniform Orifice Case. In traditional PWR design, orifices are used to manage the distribution of coolant flow based on the power distribution. Following this example, this study developed an orifice pattern in which larger orifice sizes are applied to hot channels to deliver more flow and lower moderator temperatures to prevent reversal. This approach leads to larger orifice flow area ratios and lower overall pressure drops. The following results show comparison between a varied orifice case and a uniform orifice case without reversal $(r=0.15)$.

The variation of area ratio $r$ is chosen based on the expectation of higher assembly power for the most reactive (fresh) assemblies. Table 3 shows the $r$ value of each assembly. The results of the varied $r$ case are similar to those of $r=0.15$ case, although they show a slightly higher degree of power peaking among assemblies. Figure 5 shows the moderator flow rate, equivalent density, and assembly power across the quarter core of the two cases and Figure 6 compares the power and temperature profiles in corresponding channels. These results demonstrate that varied orifice sizes can prevent reversal with a larger orifice size that is required for the uniform orifice size solution.

\section{Discussion}

In the current US reference design, changing the orifice size can prevent flow reversal and manage axial power peaking at steady state condition. However, the assembly power peaking 

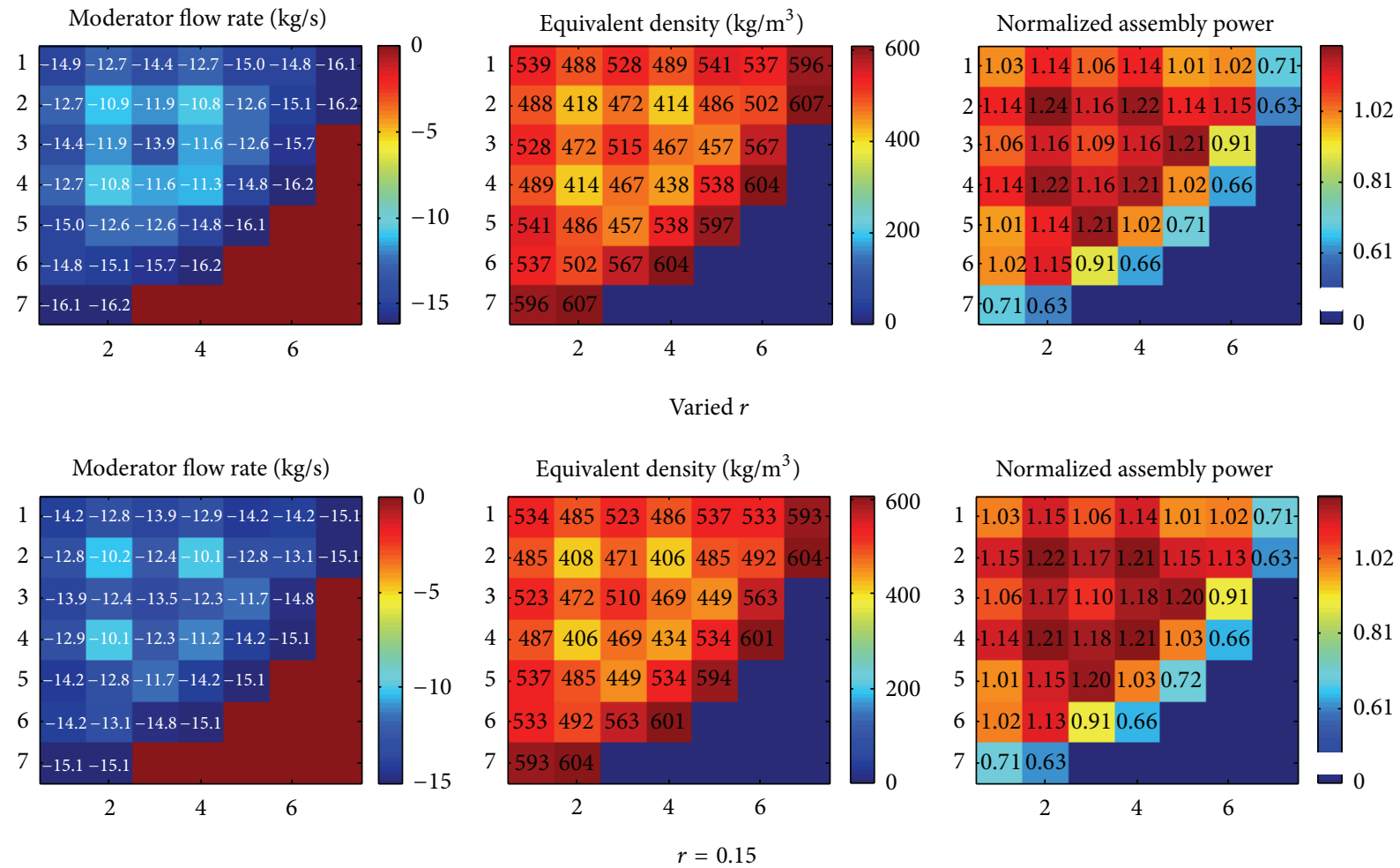

Figure 5: Moderator flow rate, equivalent density, and normalized assembly power (reference value $24.59 \mathrm{MW}$ ) in varied $r$ case and $r=0.15$ case.
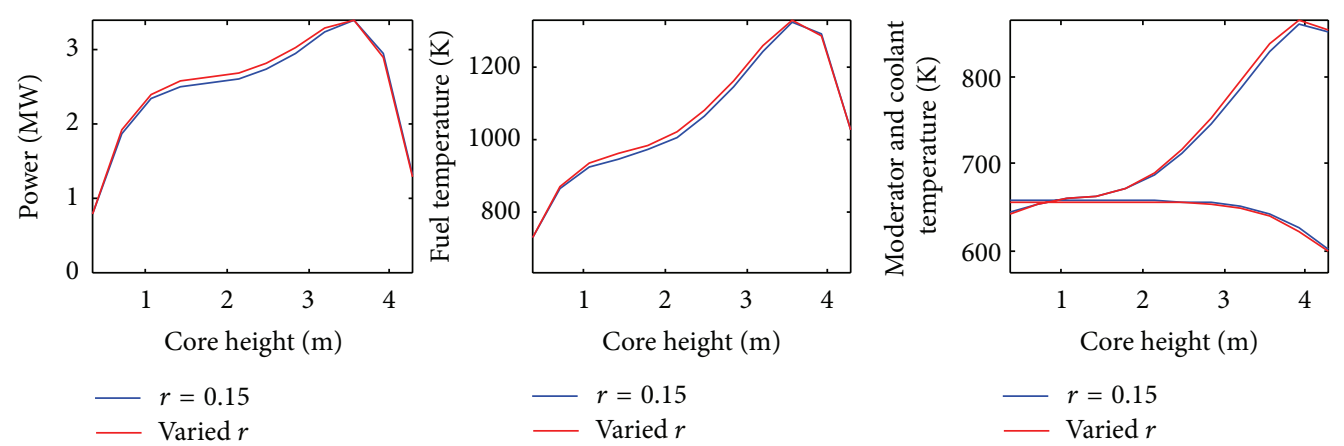

Figure 6: Power, fuel temperature and moderator, and coolant temperature in hot channel in varied $r$ case and $r=0.15$ case.

is large and may lead to detrimental hot spot effects. And furthermore, the reversal during depletion can be moderated by using control rods, burnable absorbers, and varying the fuel enrichment in the further analysis.

Noticing that the density change across the supercritical point has a tendency to reverse the moderator flow, as in Oka's original design, the water rods are insulated from the hot coolant of the fuel, which is surrounded by almost stagnant water which has an insulation cover around, to provide adequate moderation; the same kind of reversal should be avoided in such design. However, these insulated water rods are replaced with the similar water rods with US reference SCWR in his later designs $[1,10]$. While in mixed spectrum reactor design, which separates the higher density/higher moderation water and lower density/moderation water to thermal and fast zones, this kind of reversal can be mitigated, though the reversal due to other effects still appeared during the accidents $[5,12]$.

\section{Conclusion}

A coupled code package, PARCS and RELAP5, is introduced to study the SCWR reactor core. Flow reversal in downward flowing moderator channels is found using the coupled codes. The reason of the reversal is the buoyancy and density change across the supercritical point. Using both uniform and nonuniform orifices in moderator channels to prevent the reversal is studied. Results showed that, with uniform orifices, 
orifice-moderator area ratio less than 0.18 is needed; with nonuniform orifice, higher area ratio can prevent the reversal.

\section{Nomenclature}

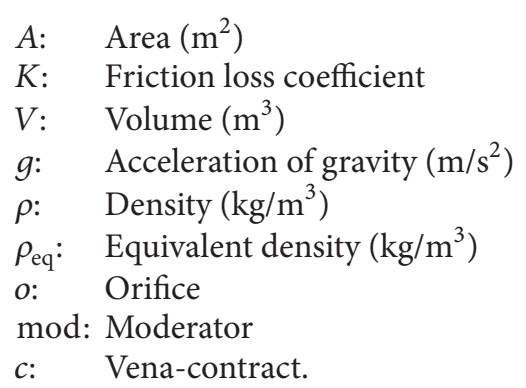

\section{Conflict of Interests}

The authors declare that there is no conflict of interests regarding the publication of this paper.

\section{Acknowledgments}

The authors would like to thank the sponsors, Nuclear and Radiation Safety Center of Ministry of Environment Protection of China, with Project no. ZD1301-WXHT-011, and Ministry of Education of China with Project no. 20100073120049.

\section{References}

[1] Y. Oka and S. Koshizuka, "Supercritical-pressure, once-through cycle light water cooled reactor concept," Journal of Nuclear Science and Technology, vol. 38, no. 12, pp. 1081-1089, 2001.

[2] J. Yoo, Y. Ishiwatari, Y. Oka, and J. Liu, "Composite core design of high power density supercritical water cooled fast reactor," in Proceedings of the Global International Conference, Tsukaba, Japan, 2005, Paper: 246.

[3] J. Buongiorno, "Progress report for the FY-03 Generation-IV R\&D activities for the development of the SCWR in U.S.", Tech. Rep. INEEL/EXT-03-01210, 2003.

[4] T. K. Kim, P. P. H. Wilson, P. Hu, and R. Jain, "Feasibility and configuration of a mixed spectrum supercritical water reactor," in Proceedings of the Physics of Fuel Cycles and Advanced Nuclear Systems-Global Developments (PHYSOR '04), pp. 1513-1523, Chicago, Ill, USA, April 2004.

[5] Z. H. Xu, D. Hou, S. W. Fu, Y. Yang, and X. Cheng, "Loss of flow accident and its mitigation measures for nuclear systems with SCWR-M," Annals of Nuclear Energy, vol. 38, no. 12, pp. 26342644, 2011.

[6] P. MacDonald, "Feasibility study of supercritical light water cooled reactors for electric power production," Idaho National Engineering and Environmental Laboratory Report INEEL/ET04-02530, 2005.

[7] T. Downar, D. Lee, Y. Xu, T. Kozlowski, and J. Staudenmier, PARCS v2.6 U.S. NRC Core Neutronics Simulator User Manual Draft (11/10/04), 2004.

[8] HELIOS manual, Scandpower, 1997.

[9] P. P. H. Wilson and P. Hu, "Reactor analysis for counterflowing moderator and coolant in a supercritical water reactor," in Proceedings of the 14th International Conference on Nuclear Engineering (ICONE '06), Miami, Fla, USA, July 2006.

[10] K. Kamei, A. Yamaji, Y. Ishiwatari, Y. Oka, and J. Liu, "Fuel and core design of super light water reactor with low leakage fuel loading pattern," Journal of Nuclear Science and Technology, vol. 43, no. 2, pp. 129-139, 2006.

[11] RELAP5 manual, vol. 1, pp. 193, July 2003.

[12] D. H. Zhu, W. X. Tian, H. Zhao, Y. L. Su, S. Z. Qiu, and G. H. Su, "Comparative study of transient thermal-hydraulic characteristics of SCWRs with different core design," Annals of Nuclear Energy, vol. 51, pp. 135-145, 2013. 


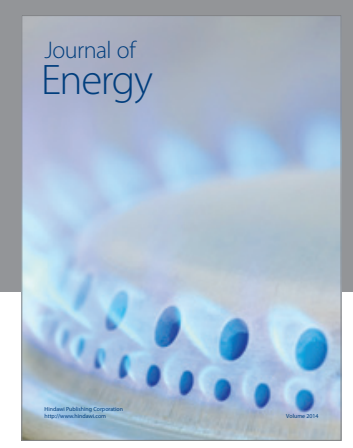

Journal of

Industrial Engineering
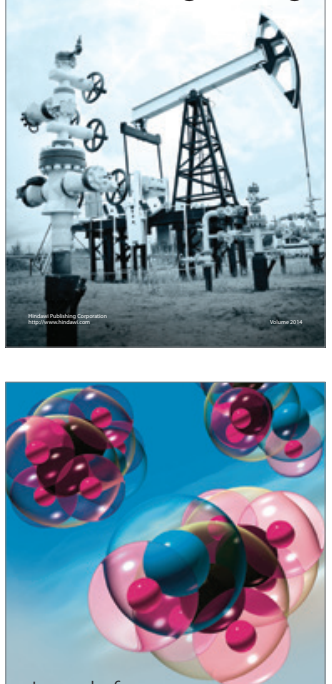

Fuels
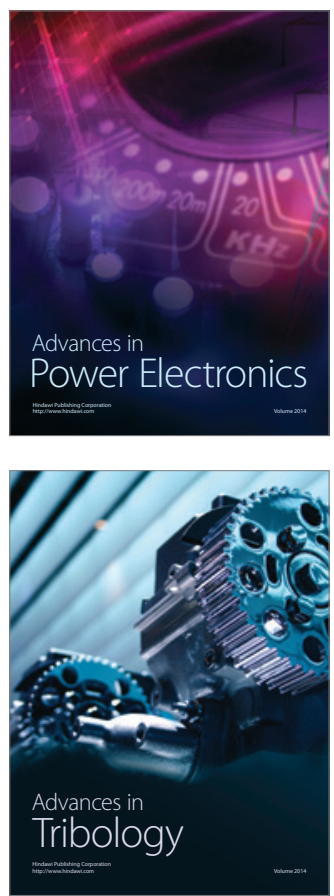

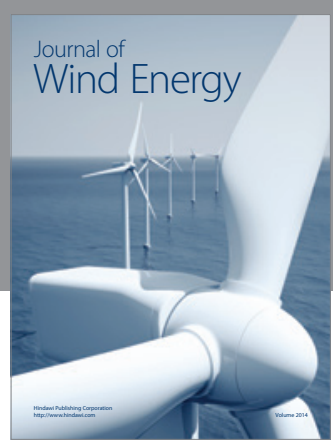

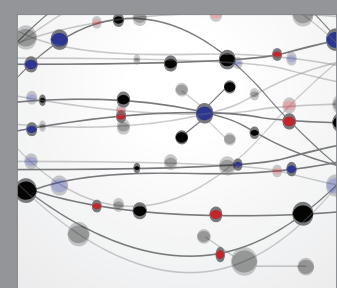

The Scientific World Journal

Submit your manuscripts at http://www.hindawi.com

Journal of

Structures
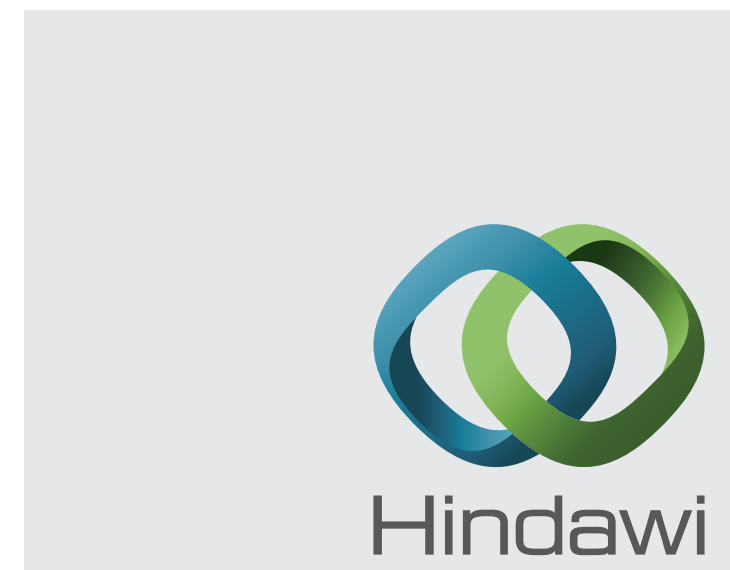

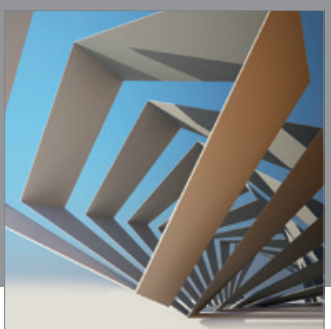

Rotating

Machinery
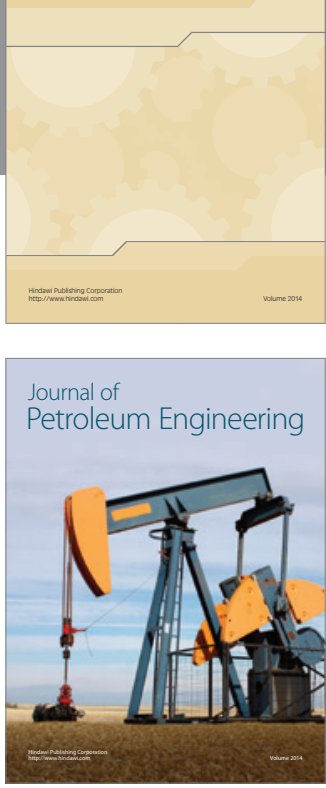

Journal of

Solar Energy
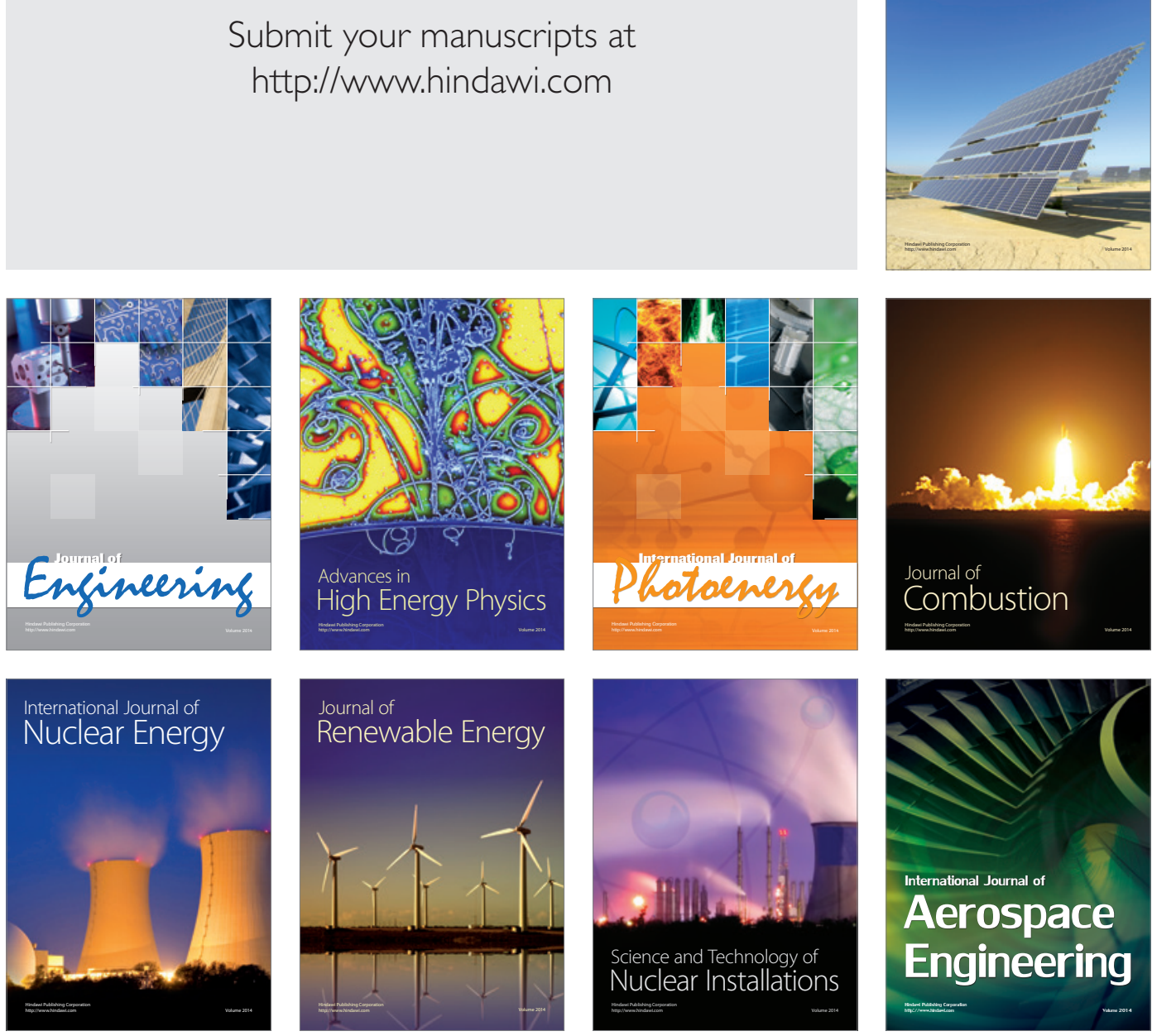